\title{
EXPERIMENTAL AND NUMERICAL INVESTIGATION OF FLOW HYDRAULICS AND Pipe GeOMETRY ON LEaKage BEHAVIOR OF LAbORATORY WATER NETWORK DISTRIBUTION SYSTEMS
}

\author{
Tamer Nabil $^{1 *}$, Fahad Alhaddad ${ }^{1}$, Mohamed Dawood $^{1}$, Osama Sharaf ${ }^{1}$ \\ ${ }^{l}$ Mechanical Engineering Dept., Faculty of Engineering, Suez Canal University, Ismailia, Egypt \\ ${ }^{*}$ Corresponding author: Tamer Nabil \\ Emails: tamer_mtc@yahoo.com,tamir.nabil@eng.suez.edu.eg
}

\begin{abstract}
As the leakage behavior of water distribution network is considered life-threatening and critical issue, so the behavior of water distribution network system is investigated experimentally and numerically under the effect of different positions and flow rates of leakage outlets taking into consideretion the flow hydraulics and pipe geametry. A laboratory model of the real studied water distribution network is constructed. The laboratory water distribution network is horizontal and has 16 loops with total length $30 \mathrm{~m}$ and different diameters. The leakage position in the laboratory water distribution network is altered between main, sub-main and branch pipelines with different flow rates. The characteristics of the ideal laboratory water distribution network with no-leakage are studied first. The studied laboratory water distribution network system parameters are solved theoretically using Hardy-Cross method with seven iterations. The studied water distribution network system was simulated using computational fluid dynamics technique Ansys Fluent 18.2. The aim is to modify the ancient water distribution network by sensing the pressure values using dispersed pressure sensors. Also, from the pressure map of the laboratory water distribution network, the leakage position if exist can be localized. Depending on the sensed pressure, the control circuit programmed to close the corresponding solenoid valves. The leakage flow rates are $0.1,0.25$ and $0.4 \mathrm{~L} / \mathrm{s}$ and changed between the main and sub-main pipes. The maximum pressure drop around 500pa at the node directly preceding the leakage point at leakage flow rate $0.4 \mathrm{~L} / \mathrm{s}$. The performance of the used solenoid valve is simulated using Matlab-Simulink technique. The simulation results show the response to step down control signal is over damped with steady state error $2 \%$ and settling time $0.6 \mathrm{~s}$.
\end{abstract}

Keywords: Water distribution network, Water leakage, Solenoid valve, Computational Fluid Dynamics (CFD), Matlab.

\section{INTRODUCTION}

A consistent supply of clean water is the first and most critical community service that people need. A safe supply of potable water is the basic necessity of mankind; therefore, water supply systems are the most important public utility (Creaco and Pezzinga, 2018). The network distribution system is used to supply water from its source to the point of usage (Ahmad Fuad et al., 2019). The leakage is defined as (amount of) water which escapes from the pipe network by means other than through a controlled action. 
Meniconi et al., 2013 explained the analysis concerning the importance in numerical models of unsteady friction and viscoelasticity to transients in plastic pipes with an external flow due to a leak. Tests are based on laboratory experiments, and the use of different numerical models. Daniel Paluszczyszyna, et al., 2015 Modeled and simulated the water distribution systems with quantised state system methods (QSS). Daniel Paluszczyszyn et al., 2015 developed the water network model reduction software. The application can be integrated with other concepts applied to water distribution system or it can be used as a standalone tool for the purpose of the model simplification only. Creaco and Pezzinga, 2018 explored the simulation and optimization modelling, topology and partitioning, water quality, and service effectiveness. Creaco and Pezzinga, 2014 showed how pipe replacements and control valve installations can be optimized in water distribution networks to reduce leakage, under minimum nodal pressure constraints. Santonastaso et al., 2019 proposed a general framework to adjust water distribution network (WDN) partitioning algorithms to account for the real positions of isolation valves. Avi Ostfeld, 2015 verified that the water distribution system is a complex assembly of hydraulic control elements connected together to convey quantities of water from sources to consumers. Alsharqawi et al., 2020 studied the aging water distribution networks in the US to verify that they are approaching the end of their useful life, and more than 240,000 pipeline breaks are estimated to occur every year. Starczewska et al., 2015 showed the common existence of pressure transients in operational water distribution systems requires their characterization and assessment of their impact by evidencing the occurrence and the differences in pressure transient behavior in complex WDS.

Del Giudice and Di Cristo, 2003 showed three different sensitivity-based methods for selecting the worthwhile sensor location in water distribution network. The results show that there are no marked differences between the three methods. Kumar et al., 2010 presented that the estimation of pipe roughness coefficients is an important task to be carried out before any water distribution network model is used for online applications. Galuppini et al., 2019 displayed that real time pressure control is commonly adopted in water distribution network management to reduce leakage. A numerical description of the dynamic behavior of the water distribution network (WDN) is introduced. Misiunas et al., 2006 presented an algorithm for the burst detection and location in water distribution networks based on the continuous monitoring of the flow rate at the entry point of the network and the pressure at a number of points within the network.

Fontana et al., 2017 indicated that a common strategy for leakage reduction in water distribution networks (WDNs) is the use of pressure reducing valves (PRVs). As well known, a relationship between pressure and water losses can be established, according to which reducing pressure results in reduced losses. Quraishi and Al-Dhowalia 1994 demonstrated a practical and more reliable approach for assessment of leakage from Riyadh water distribution network. It presents the methodology and discusses the result of the field study of ten selected areas of the city. Chiplunkar et al. 1990 Analyzed the looped distribution networks which is a prerequisite in design or reorganization of water supply systems. Constantin et al., 2011 reasoned the transient movement results as a hydraulic system response to sudden valve maneuvers in a water supply network. Numerical and experimental investigation on pressure variation was carried out. 
Choi et al., 2020 claimed the water distribution systems in Korea are responsible for maintaining a stable supply of tap water and ensuring water quality are experiencing many problems, such as pipe leakage, corrosion, and aging of pipes. Paez et al., 2018 proposed a non-iterative method to perform the simulation of water distribution systems with pressure driven demands using EPANET2 without the need to use its programmer's toolkit. Straka et al., 2010 studied the distribution networks and their classification and showed that there is a possible connection between the producers and consumers in two categories. The first is the economy side, the other side is the production distribution. Latchoomun et al., 2015 proposed a novel model development of old water distribution networks based on estimation of the leakage from MNF and the burst frequency of AZPs.

Mair et al., 2014 analyzed the impact and effect of improving the data from other sources for creating water distribution system models. These Investigations showed that hydraulic WDS models with a mean pressure error of $3 \mathrm{~m}$ can be created by knowing a percent of $30 \%$ of pipes with a diameter $\geq 250 \mathrm{~mm}$. Athanasios et al., 2009 presented the description of the technical and physics of the AE leak detection methodology going to its pros and cons and all the requirements of this technique. Mircea Dobriceanu 2008 performed a SCADA system for the water distribution stations to monitor and control of the technological parameters. Konnur et al., 2016 made quick review for the methods of analyzing and design of multi reservoir multi junction water transmission networks that is considered to be one of the vital elements for every water supply system. D'Ambrosio 2015 studied mathematical programming methods in water networks optimization. Between the major topics they focused on two different and related problems. One described by the notion of network design, while the other one is more applied in terms of network operation. Marko Blažević et al., 2005 investigated the various methods of leak detection in underground network of municipal water distribution system.From the previous survey and discussed papers, the authors claimed that there is a gap in the leakage behavior investigation of small water distribution network with the effects of flow hydraulics and pipe geometry. Also, the gap of the possible treatment ways with leakages especially in aged water distribution network. The used pressure sensors permit the authors to figure out the pressure distribution in conventional (ideal) network and network with leakages. Moreover, the water distribution network pressure map can be drawn in two cases, ideal with no-leakage and with leakage cases, to standardize the leakage effect. The network performance is investigated in two cases; at peak hours and off peak hours. The water distribution network is modified with control circuit to sense the pressure values and close all pipelines directed to the leakage outlets by solenoid valves if required. Finally, the study of the water distribution network used theoretical, experimental and numerical techniques to obtain the behavior of small laboratory water distribution network with and without leakage effects. Also, the simulation of the used solenoid valve enables the estimation of the secondary leakage through these valves.

\section{THEORETICAL BACKGROUND}

With respect to distribution network analysis, the conventional theoretical solution is known as the Hardy-Cross method (Hardy Cross, 1936). The Hardy Cross method is an iterative technique for equations of flow; continuity of flow (the flow in is equal to the flow out at each junction) and continuity of potential (the total directional head loss along any 
loop in the system is zero) (El-Zahab and Zayed, 2019). The Hardy Cross method depends on simple mathematics and it iteratively corrects the mistakes in the initial guess used to solve the problem (self-correcting) (Volokh, 2002). The theoretical results of Hardy Cross method are obtained after seven iterations and listed in Table 2.

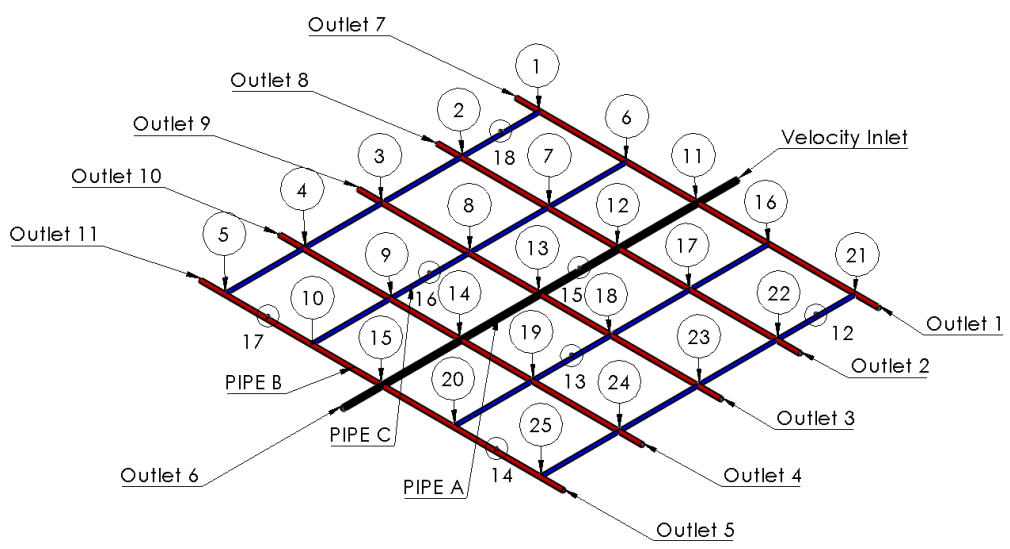

Fig.1 CAD drawing of the laboratory distribution network

\section{EXPERIMENTAL WORK}

Fig.1 shows the CAD drawing and Fig.2 shows the photo of the laboratory water distribution network. The studied water distribution network consists of main, sub-main, branch pipelines and branching nodes that creating 16 loops. The main pipeline has 1 inch diameter and $3 \mathrm{~m}$ length, the sub-mains have 0.75 inch diameter and $12 \mathrm{~m}$ total length and the branches have 0.5 inch diameter and $15 \mathrm{~m}$ total length. Ball valves are used in the laboratory water distribution network to control the flow rate and direction.
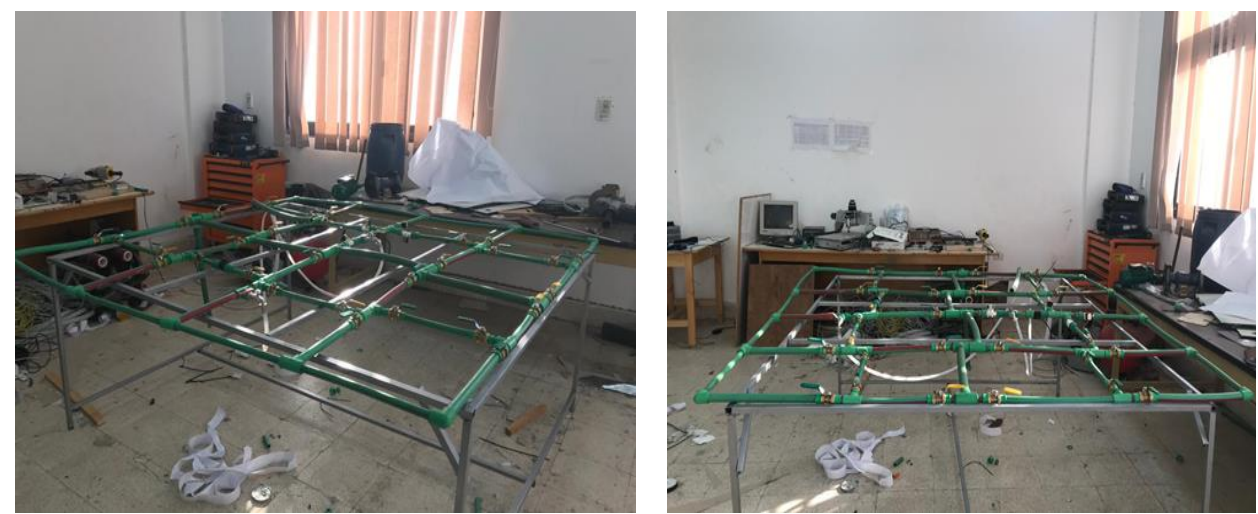

Fig.2 Real photo of the laboratory water distribution network

Fig. 3 shows the ball valve which installed to discharge the water with different flow rates exit from the water distribution network as a leakage. The leakage ball valve is placed in the main and sub-main pipelines to investigate experimentally the most critical leakage cases in the water distribution network analysis. 


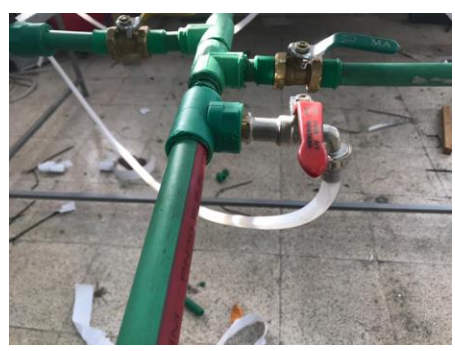

Fig.3 Photo of the ball valve at the main pipeline to simulate the leakage outlet

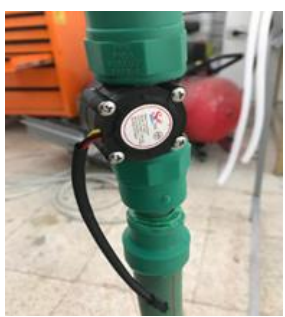

(a) Flow meter sensor

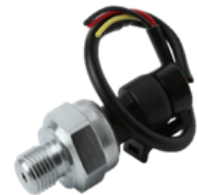

(b) Pressure sensor

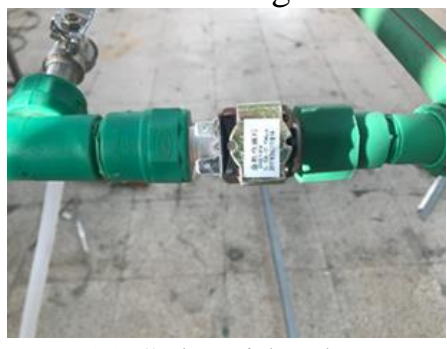

(c) Solenoid valve

Fig.4 Photos of sensors and valve of the laboratory water distribution network

Table 1. Specifications of flow meter sensor, pressure sensor and solenoid valve

\begin{tabular}{|c|c|c|}
\hline $\begin{array}{c}\text { Flow meter sensor } \\
\text { (Sea YF-S201) } \\
\text { (www.seagroup.com) }\end{array}$ & $\begin{array}{c}\text { Pressure sensor } \\
\text { (Flying Elephant SE0006) } \\
\text { (www.flyingelephant.lk) }\end{array}$ & $\begin{array}{c}\text { Solenoid valve } \\
\text { (Adafruit ADA997) } \\
\text { (www.adafruit.com) }\end{array}$ \\
\hline $\begin{array}{l}\text { Range:1-30 L/min } \\
\text { Water pressure: } \\
\leq 1.75 \mathrm{MPa} \\
\text { Working voltage } \\
\text { range: DC } 5 \sim 18 \mathrm{~V} \\
\text { Load capacity: } \leq 10 \\
\mathrm{~mA} \text { (DC 5V) } \\
\text { Operating } \\
\text { temperature range: } \\
\leq 80^{\circ} \mathrm{C} \\
\text { Operating humidity } \\
\text { range: } 35 \% \sim 90 \% \mathrm{RH} \\
\text { (no frost) }\end{array}$ & $\begin{array}{l}\text { Supply voltage:5.0VDC } \\
\text { Output: } 0.5 \sim 4.5 \mathrm{VDC} \\
\text { Working current: } \leq 10 \mathrm{~mA} \\
\text { Pressure range: } 0 \sim 1.2 \mathrm{MPa} \\
\text { Proof Pressure: } 2.4 \mathrm{MPa} \\
\text { Burst Pressure: } 3.0 \mathrm{MPa} \\
\text { Op. Temp.: } 0 \sim 85^{\circ} \mathrm{C} \\
\text { Storage Temp.: } 0 \sim 100^{\circ} \mathrm{C} \\
\text { Measure error: } \pm 1.5 \% \mathrm{FSO} \\
\text { Full temp. range error: } \\
\pm 3.5 \% \mathrm{FSO} \\
\text { Response: } \leq 0.9 \mathrm{~S}\end{array}$ & $\begin{array}{l}\text { 1/2" nominal NPS } \\
\text { Working pressure of fluid: } \\
0.02-0.8 \mathrm{Mpa} \\
\text { Working temperature of } \\
\text { fluid: } 1^{\circ} \mathrm{C}-100^{\circ} \mathrm{C} \\
\text { Voltage: } 6 \mathrm{VDC} \text { to } 12 \mathrm{VDC} \\
\text { Current: } 500 \mathrm{~mA} \\
\text { Materials: Stainless } \\
\text { Steel/Poly-oxy-methylene } \\
\text { Operating mode: Normally } \\
\text { closed } \\
\text { Filter Screen: Stainless Steel } \\
\text { Inlet Filter } \\
\text { Usage: Water }\end{array}$ \\
\hline
\end{tabular}

The measured pressure values via pressure sensors are transferred instantaneously to be recorded on the computer to give a real picture of the pressure map through the whole network. One flow meter is fixed and changed between the main, sub-main and branch pipelines to measure the flow rates (Fuad et al., 2019). A control unit is designed with code programmed using the Arduino for a specified function. As the pressure sensors sense the pressure drop to a certain setting value, the signal from control unit initiate the solenoid 
valves to close all pipelines which directed the flow to the leakage outlet. Meanwhile, this technique is important to save considerable amounts of water losses. The studied laboratory water distribution network meets all the requirements of the model (geometrically, kinematically and dynamically similar) except it constructed horizontally in the laboratory with no potential head and neglected hydraulic gradient energy.

Fig. 4 and Table 1 illustrate the components and their specifications of the studied laboratory water distribution network. The flow is discharged from water tank to the water distribution network by $1 / 2 \mathrm{hp}$ centrifugal pump $(\mathrm{H}=18 \mathrm{~m}, \mathrm{Q}=22 \mathrm{~L} / \mathrm{min}$ and $2850 \mathrm{rpm})$.

\section{1. control circuit and algorithm}

Pressure measurements are recorded by pressure sensors through Arduino Mega. When the leakage is started, this causes a pressure drop and the controller determines the location of the leakage and defines the pipe number from the node where the pressure is decreased. Then controller sends a signal to close all the solenoid valves in pipelines which directs the water flow to leakage location. Also, an alarm is sent to the related person about the leakage location. Fig.5 shows the flow chart of the control algorith. Fig.6 shows the schematic of wiring and connections of the control circuit components and the interaction communicating signals between these components. These two figures summarize the used methodology of the studied experimental work.

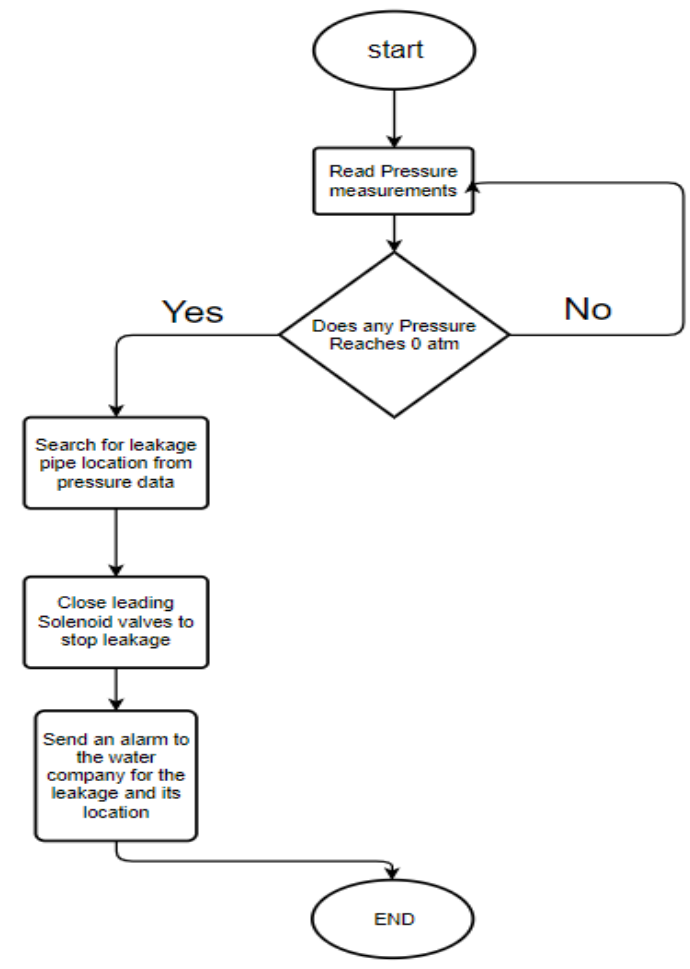

Fig.5 Flow chart of Arduino control algorithm to control the leakage by solenoid valves using pressure signals 


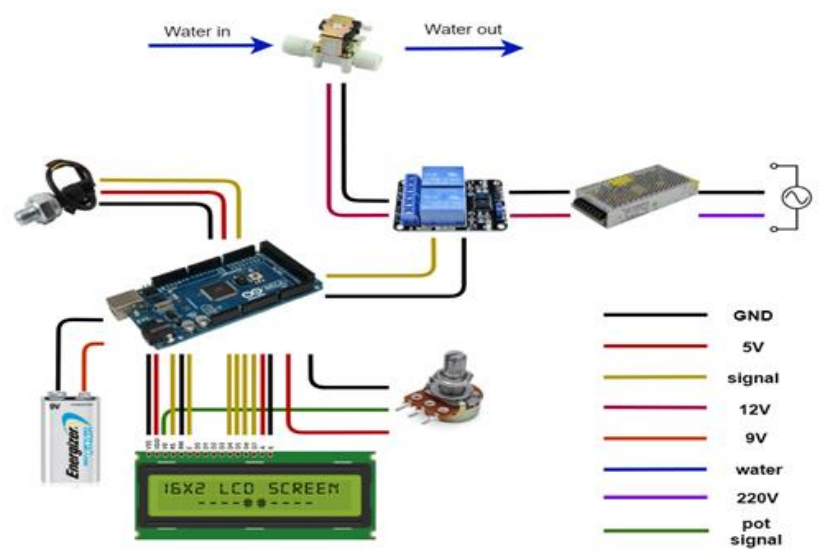

Fig.6 Schematic drawing of the network control circuit

The control circuit consists of; relay module (2 channel), Arduino Mega 2560 R3, relay driver module RK4, Power distributer, LCD and Volt Current monitor gauge DSN-VC288.

\subsection{Experimental Procedures}

In small scale network like that under consideration, the friction is high and consequently the losses are also high and this is a general trend in small pipes. Also, all the fittings, elbows and other minor losses sources have a considerable effect. The most influenced pipelines of the network due to leakage must be determined, hence the leakage has different impact on the pipelines of the network. The response of the solenoid valve to the control signal command must be investigated.

The experimental test is performed for conventional laboratory water distribution network without leakage. The pressure and flow rate values in different nodes and pipelines are recorded as reference values. Open the ball valve which discharges the water out of network as a simulation of leakage. The throttle area of the ball valve is adjusted to certain leakage flow rate by measuring the water volume in calibrated container and stop watch to measure the time. After adjusting the leakage flow rate, the solenoid valves at leakage position are observed to determine its speed of response. The leakage flow rate is changed and the values of flow rates and pressures are recorded and the response of the solenoid valves are detected ( Ferrante et al., 2012).

\section{NUMERICAL SIMULATIONS}

The numerical simulations are performed in case of no leakage of the water distribution network to enable the detection of the ideal behaviour of the network, as a first case (Loan Sarbu, 2010). After that, the computations are performed with leakages at different positions in the network, as a second case (Chandapillai et al., 2011).

The numerical model was mapped on a commercial CFD solver Ansys fluent 18.2. Parametric studies of velocity, pressure and eddy viscosity profiles are investigated. Also, vector display of water flow along the different locations of the network (pipes and nodes) gives a detailed picture of the flow in the network. The Phase coupled SIMPLE (PC- 
SIMPLE) algorithm was used for the pressure-velocity coupling discretization while the body force is used for pressure discretization (Afifi et al., 2018).

The initial conditions were; Uniform fully developed velocity profile at pipe inlet. Firstorder upwind discretization scheme was used for the momentum equations, turbulence kinetic energy $(\mathrm{k})$, and turbulence dissipation rate $(\varepsilon)$. All the iterative solutions were performed in double precisions. An inlet flow rate boundary condition was used at the pipe inlet (Greyvenstein and Van Zyl, 2007). Using flow rate at inlet $(0.1,0.25$ and $0.4 \mathrm{~L} / \mathrm{s})$ and pressure at outlet (atmospheric pressure) as boundary conditions are the common way of formulating pipe network flow problems. The usual no-slip boundary condition was adopted at the pipe wall. To avoid divergence, under-relaxation technique was applied. The under-relaxation factor for pressure was 0.3 , for momentum was 0.6 , and these for turbulence kinetic energy and its dispassion rate were 0.8 . The solution was assumed to have converged when the continuity and velocity residuals reached nearly $10^{-4}$ which is a promising value in the solution according to Ansys fluent manual. The numerical solution typically required 480 iterations (Van Zyl and Clayton, 2007).

The water distribution network consists of 1" pipe with inner diameter of $26.24 \mathrm{~mm}$ and length $2500 \mathrm{~mm}$ which is the main pipe, 0.75 " pipe with inner diameter of $20.57 \mathrm{~mm}$ and length $1000 \mathrm{~mm}$ which are the sub-main pipes, 0.5 " pipe with inner diameter of $15.47 \mathrm{~mm}$ and length $500 \mathrm{~mm}$ which are the branches pipes and for leakage a $12 \mathrm{~mm}$ inner diameter pipe was assumed as a source of leakage. All these pipes and their fittings are PVC.

Fig.7 shows the locations of the leakage in the water distribution network. The number of leakage outlets is 7 . One leakage position at the main pipeline (number 15), two leakage positions at the sub-main pipelines (number 14 and 17, symmetric positions), two leakage positions at external branches pipelines (number 12 and 18, symmetric positions) and two leakage positions at internal branches pipelines (numbers 13 and 16, symmetric positions).

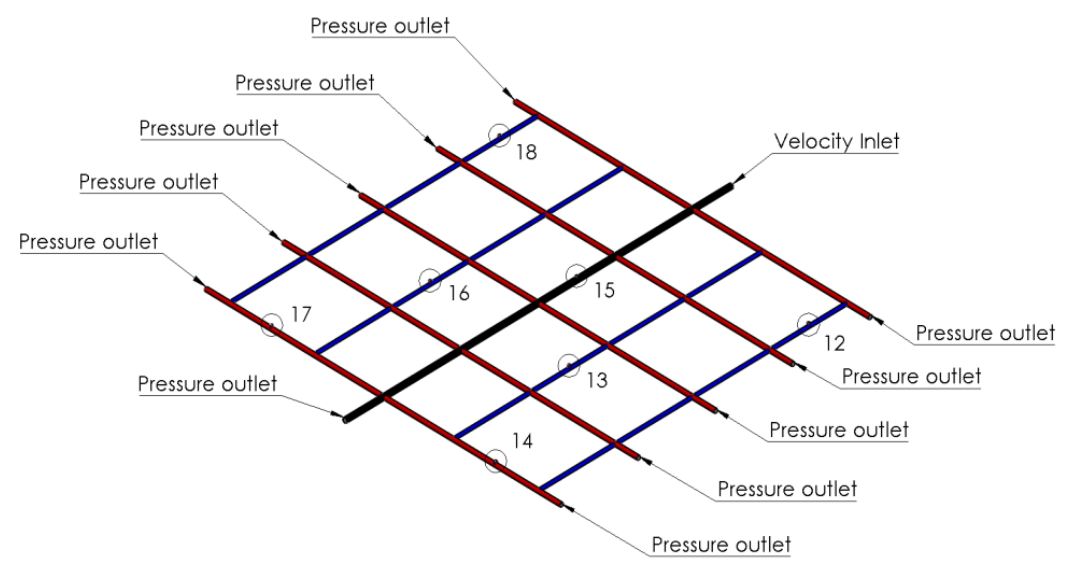

Fig.7 Water distribution network leakage outlet locations

Fig.7 also shows the distribution network boundary conditions. The boundary conditions are assumed to have an inlet velocity at $2 \mathrm{~m} / \mathrm{s}$, and outlets with atmospheric pressure. All turbulence parameters were set to $1 \%$ turbulent intensity with equivalent hydraulic diameter. 
Fig.8 demonstrates that the meshing was done in ICEM CFD using blocking technique with one million Hexa elements, with angle quality criteria greater than 27 and determinant $2 \times 2 \times 2$ quality criteria greater than 0.3 which are acceptable according to ICEM CFD user manual for Fluent solver (http://www.ansys.com, 2013).

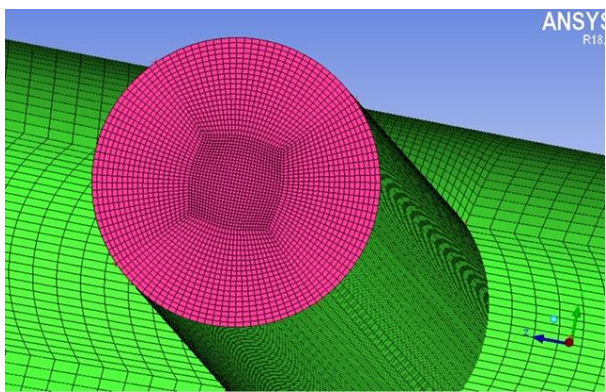

(a) Leakage outlet mesh

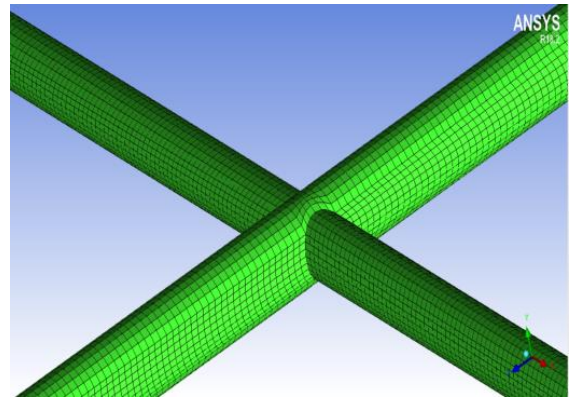

(b) Zoom in mesh at any node

Fig.8 Distribution network mesh configuration

236 The mesh grid stability test was carried out in order to insure accurate simulation results 237 with precision and to save the required simulation time. The model was tested using three different mesh numbers to obtain mesh grid stability and variables steadiness at the optimum mesh grid number. The pressure value at different nodes is the chosen parameter to determine the required mesh number. Fig.9 shows that 1 million elements are acceptable number of meshes due to the changed variables (node pressure) become constant at this number (Brki and Praks, 2019).

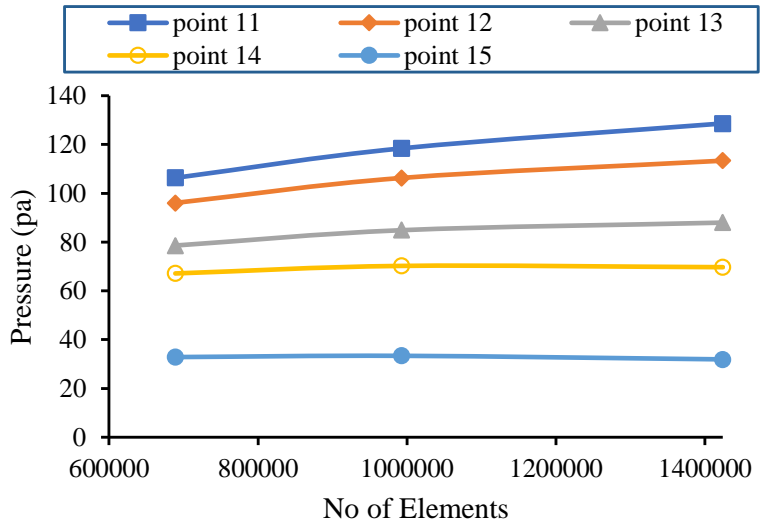

Fig.9 pressure variations with mesh grid numbers at network nodes 11-15

The software Ansys fluent was used for solving the governing equations. This package utilizes a method of control volume theory to convert the governing equations to algebraic equations so that they can be illuminated numerically. The governing equations (continuity, momentum and energy) associated with the standard k- $\varepsilon$ model (Turbulent kinetic energy equation, Dissipation rate equation) using the default values of the empirical constants (Launder and Spalding, 1974).

Table 2 shows the theoretical (Hardy-Cross using Darcy-Wesibach method) and numerical (Ansys, Fluent) results in case of ideal (simulated by allowing all outlets from 1 to 11 
256

opened) with no leakage in the water distribution network. The results show an agreement between the theoretical and numerical results. The theoretical calculation is an iterative method with 7 steps of iterations until the head losses in the studied loop tends to zero but the number of iterations in the numerical calculations equal 480 iterations (Brki'c, 2016).

Table 2. Theoretical and numerical flow rates at different loci of network

\begin{tabular}{|c|c|c|}
\hline Outlet no/Flow rate & Theoretical $(\mathrm{Kg} / \mathrm{s})$ & Numerical $(\mathrm{Kg} / \mathrm{s})$ \\
\hline 1 & 0.1718 & 0.16182 \\
\hline 2 & 0.1365 & 0.12084 \\
\hline 3 & 0.0919 & 0.07143 \\
\hline 4 & 0.0510 & 0.04405 \\
\hline 5 & 0.0398 & 0.03052 \\
\hline 6 & 0.3779 & 0.48447 \\
\hline 7 & 0.1718 & 0.16182 \\
\hline 8 & 0.1365 & 0.12084 \\
\hline 9 & 0.0919 & 0.07143 \\
\hline 10 & 0.0510 & 0.04405 \\
\hline 11 & 0.0398 & 0.03052 \\
\hline
\end{tabular}

\section{Experimental error and uncertainty analysis}

The precision of the recorded experimental results must be investigated to be confirmed. The measuring devices must be calibrated primarily then their uncertainty can be estimated depending on their accuracy and dependent errors.

The uncertainty analysis can be calculated and depends on the error of direct measured data.

$\mathrm{U}_{\mathrm{P}}=\sqrt{\left(\frac{\partial \mathrm{P}}{\partial \mathrm{x}} \times \mathrm{U}_{\mathrm{x}}\right)^{2}+\left(\frac{\partial \mathrm{P}}{\partial \mathrm{y}} \times \mathrm{U}_{\mathrm{y}}\right)^{2}}$

Where; $U_{P}$ is the uncertainty of the studied parameter $(\mathrm{P})$ which depends on the variable parameters $(\mathrm{x}, \mathrm{y})$ and the errors of these variables $\left(\mathrm{U}_{\mathrm{x}}, \mathrm{U}_{\mathrm{y}}\right)$. Kline and McClintock, 1953 showed the experimental measuring data has certain error range depending on the accuracy of the measuring device. The measured data are water pressure, water flow rate, response time of the solenoid valve. The accuracies for used devices are listed in Table 3 according to the manufacturer.

Table 3. Uncertainty for all measuring devices.

\begin{tabular}{|c|c|c|c|c|}
\hline Device & Model & Accuracy & Range & Error \\
\hline Flowmeter Sensor & Sea: YF-S201 & $\pm 0.1 \mathrm{~L} / \mathrm{min}$ & $1-30 \mathrm{~L} / \mathrm{min}$ & $1.8 \%$ \\
\hline Pressure Sensor & $\begin{array}{c}\text { Flying Elephant } \\
\text { :SE0006 }\end{array}$ & $\pm 0.01 \mathrm{MPa}$ & $0-1.2 \mathrm{MPa}$ & $1.5 \%$ \\
\hline Solenoid Valve & $\begin{array}{l}\text { Adafruit } \\
\text { :ADA997 }\end{array}$ & $\begin{array}{c}\text { Response time } \\
\text { (open): } \leq 0.15 \mathrm{sec} \\
\text { Response time } \\
\text { (close): } \leq 0.3 \mathrm{sec}\end{array}$ & $\begin{array}{c}\text { Pressure: } 0.02-0.8 \mathrm{Mpa} \\
\text { Temperature: } 1-100{ }^{\circ} \mathrm{C} \\
\text { Voltage: } 6-12 \mathrm{VDC}\end{array}$ & $2 \%$ \\
\hline Calibrated flask & - & $\pm 20 \mathrm{ml}$ & $0-5000 \mathrm{ml}$ & $4 \%$ \\
\hline
\end{tabular}

\section{RESULTS AND DISCUSSIONS}


Firstly, the numerical results should be validated by experimental results at different leakage flow rates of different nodes in case of leakage in main pipeline of the network. Secondly, the numerical results of the network performance and flow velocity vectors at all nodes under different leakage positions (sub-main and main) and flow rates are investigated. Finally, the performance of the solenoid valve and its time step response are investigated.

Fig.10 shows the experimental and numerical pressure results at nodes from 16 to 20 of the distribution network in case of leakage at outlet 15 located in the main pipeline. The pressures at nodes from 16 to 20 are recorded numerically and measured experimentally at different leakage flow rates at outlet 15 . Experimental and numerical results show the pressure values at nodes from 16 to 20 decrease due to the leakage flow rate increase. The difference in pressure values between the experimental and numerical have different ranges according to the nodes position. Node 18 is the highest affected pressures node, also at this node the difference between the numerical and experimental results ranges from $13 \%$ to $21 \%$. Node 18 location is in the nearest pipeline parallel to the main pipeline which contain the leakage outlet. Nodes 16, 17, 19 and 20 nearly have tiny differences between the experimental pressure results and numerical pressure results.

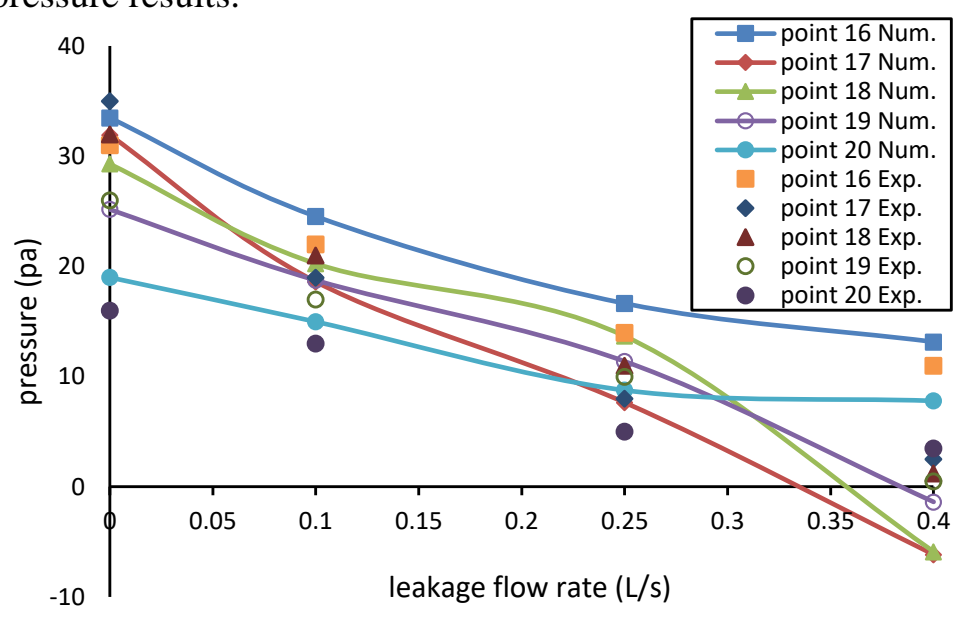

Fig.10 Validation for the numerical code with experimental work for the pressure at nodes (16-20) versus outlet 15 leakage flow rate variations 


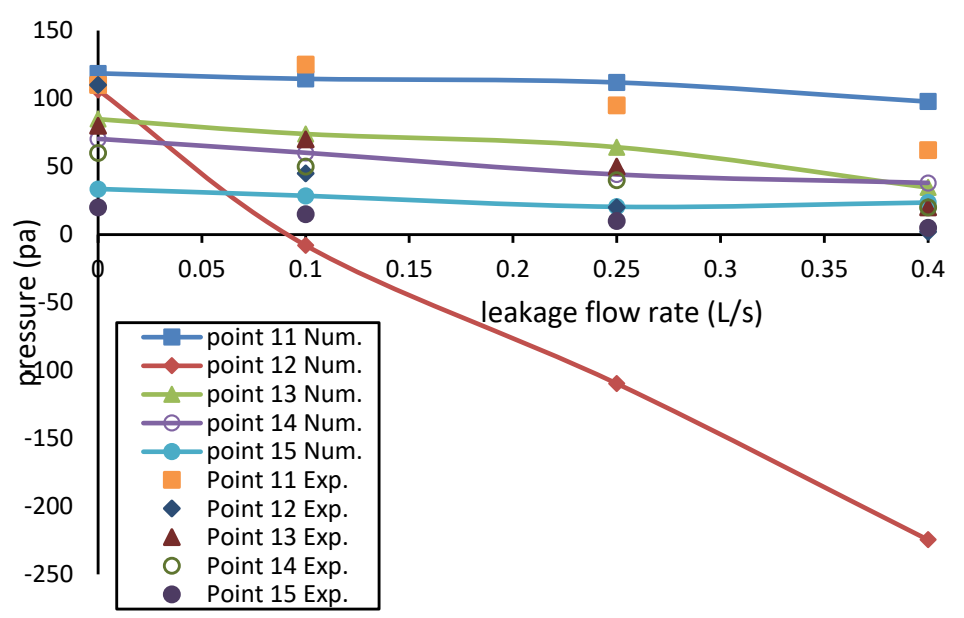

Fig.11 Validation for the numerical code with experimental work for the pressure at nodes (11-15) versus outlet 15 leakage flow rate variations

272 Fig.11 shows the experimental and numerical pressure results at nodes from 11 to 15 of the distribution network in case of leakage at outlet 15 in the main pipeline. The pressures at nodes from 11 to 15 which are located along the main pipeline of the distribution network are recorded numerically and measured experimentally at different leakage flow rates at outlet 15 . Node 13 is the highest pressure drop influenced node due to leakage flow rate variations at the main pipeline of the distribution network, also at this node the difference between the numerical and experimental results ranges from $9 \%$ to $25 \%$. Node 13 location is aligned with outlet leakage 15 and is the nearest node to this outlet.

\subsection{CFD Simulation due to Leakage at Sub-Main}

Outlet 14 of leakage outlets is located at the sub-main pipeline of the water distribution network which is perpendicular to the main pipeline and between nodes 20 and 25 . The leakage flow rate at outlet 14 can be varied to study its response on the network behavior by measuring the pressure at different network nodes. These leakage flow rate variations enable us to draw a map of pressure variations in the network to locate the most affected regions and record the different network effects with this leakage position. 


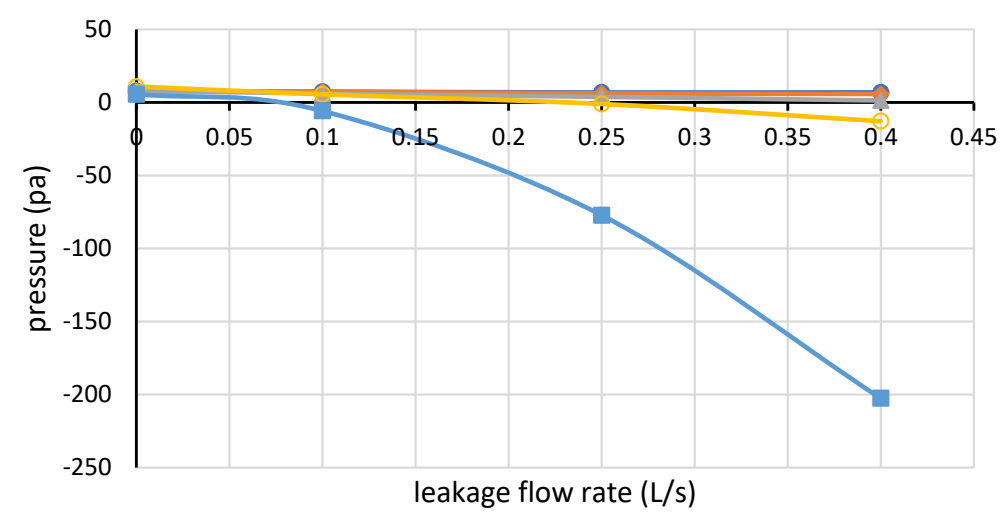

$\multimap$ point $21 \multimap$ point $22 \multimap$ point $23 \multimap$ point $24-$ point 25

Fig.12 Pressure at nodes (21-25) versus outlet 14 leakage flow rate variations

Fig. 12 shows the pressure variation at nodes from 21 to 25 with leakage flow rate variation at leakage outlet 14 . As the leakage flow rate at outlet 14 increases the pressure at node 25 extremely influenced and decreases sharply especially at high leakage flow rate because this node located at the start or the end (according to the flow directions) of the corresponding sub-main containing the leakage outlet. Nodes 21, 22, 23 and 24 have small pressure variation effect with leakage flow rate variation at leakage outlet 14 . Pressure at node 25 is highly affected due to this node is a corner node of the closed loop that contain the leakage location.

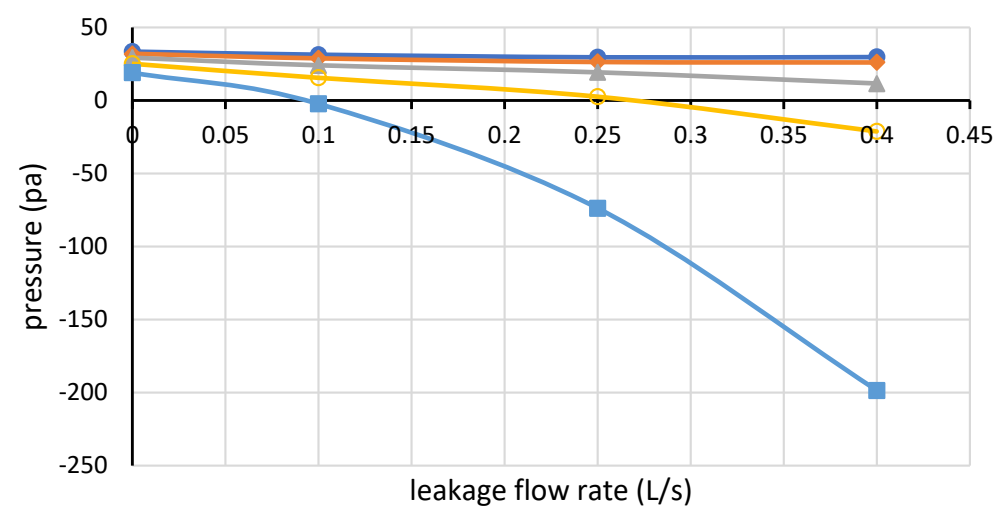

$\multimap$ point $16 \multimap$ point $17 \multimap$ point $18 \multimap$ point $19 \multimap-$ point 20

Fig.13 Pressure at nodes (16-20) versus outlet 14 leakage flow rate variations

Fig. 13 shows the pressure variation at nodes from 16 to 20 with leakage flow rate variation at leakage outlet 14 . As the leakage flow rate at outlet 14 increases the pressure at node 20 decreases sharply especially at high leakage flow rate because this node is the other end (with node 25) of the sub-main pipeline containing the leakage outlet. Nodes 16, 17, 18 
and 19 have small pressure variation effect with leakage flow rate variation at leakage outlet 14.

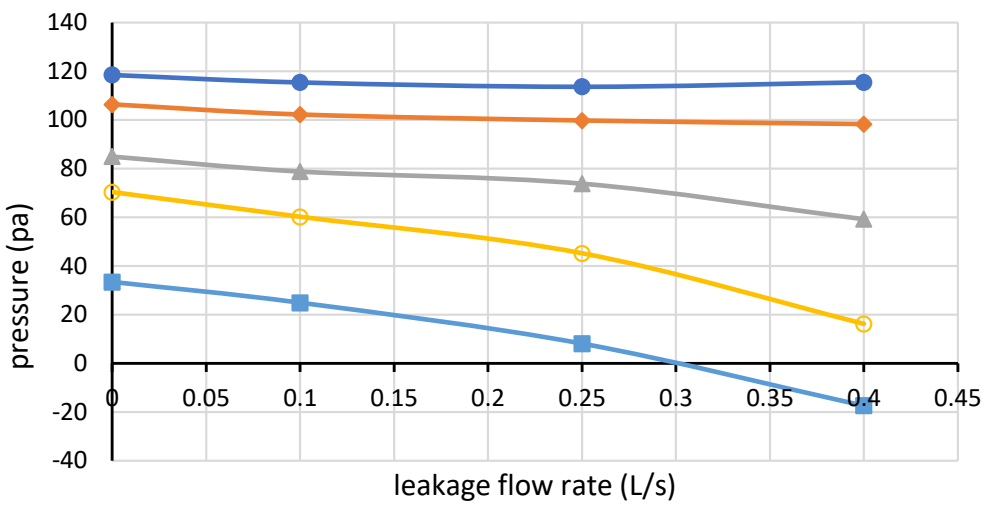

$\multimap$ point $11 \multimap$ point $12 \multimap$ point $13 \multimap$ point $14 \multimap$ point 15

Fig.14 Pressure at nodes (11-15) versus outlet 14 leakage flow rate variations

Fig.14 shows the pressure variation at nodes from 11 to 15 with leakage flow rate variation at outlet 14. The nodes from 11 to 15 are located at the main pipeline of the distribution network. As the leakage flow rate at leakage outlet 14 increases the pressure at nodes 11 and 12 nearly constant. The pressure at nodes 13,14 and 15 decrease with same trend as the leakage flow rate increase. So, the leakage flow rate variation at outlet leak point in the sub-main pipeline has apparent effect on the pressure in the main pipeline especially at nodes located at the end of the main pipeline.

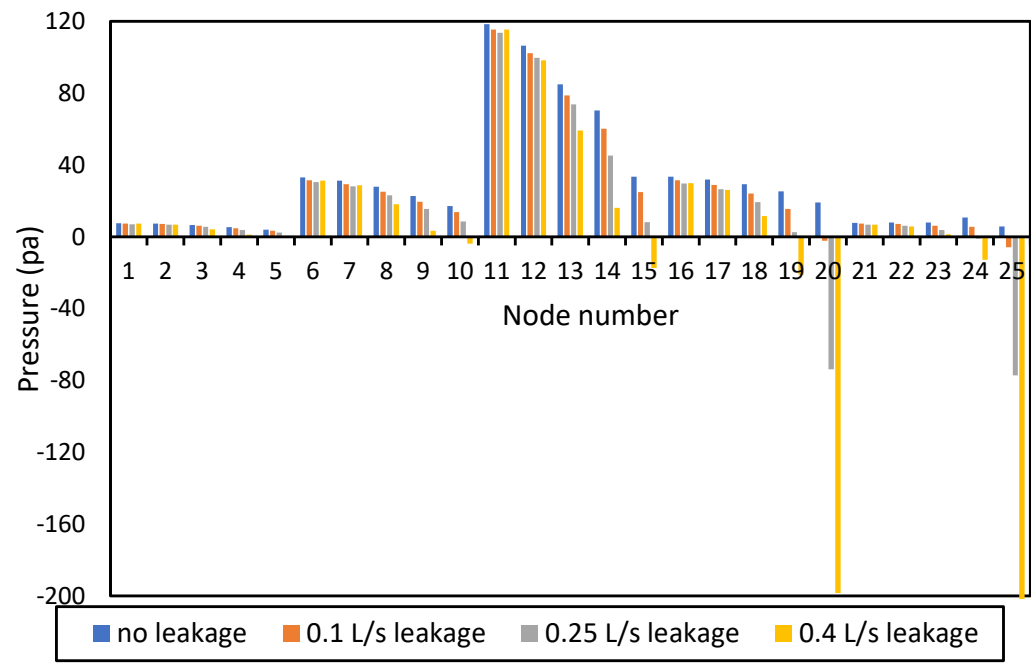

Fig.15 Histogram of pressure variations at all network nodes due to leakage flow rate variations at outlet 14

Fig. 15 is the histogram of the pressure variations at all water distribution network nodes as a result of leakage flow rate variations at designed leakage outlet 14 at the external sub- 
main of the distribution network. From the analysis of the pressure variations, the effect is observable in all nodes at alignment with the corresponding sub-main pipeline containing the leakage outlet 14 . The effect is decreased in nodes located in line parallel to the corresponding sub-main pipeline, as the distance from sub-main pipeline increases the leakage effect decreases. Also, the effect is noticeable at nodes located as apex in the closed loops that contain the designed leakage outlet 14 .

These figures indicate that each node has been affected with different performance according to the leakage position and the leakage flow rate. The negative pressure at nodes 20 and 25 indicates the pressure values at these nodes are vacuum pressures and the air bubbles are forms at these nodes which influence the streaming of the flow results in the decreasing of the flow area. Also, the negative pressure causes back flow and flow separation at these nodes as a leakage which apparent in velocity vector contours.

Fig.16 shows the velocity vectors at different nodes of the distribution network in case of leakage at outlet 14 in the external sub-main pipeline of the network. The studied pipeline alignment is in $\mathrm{x}$-axis direction which is perpendicular to the main pipeline. The maximum flow rate in laboratory distribution network is $0.4 \mathrm{~L} / \mathrm{s}$. Figs.16 (a) and (b) illustrate the velocity vectors of the fluid flow at nodes 20 and 25 . Nodes 20 and 25 are the extreme nodes of the chosen sub-main pipeline of the network containing the leakage outlet 14 . Figs.16 (a) and (b) show that the flow direction in this pipeline is directed from nodes 20 and 25 to the leakage outlet 14 due to the sudden drop in pressure value that results at leakage outlet. Also, this pipeline feeds another loop by water in negative $\mathrm{x}$-axis direction through node 20 but due to leakage the flow is reversed in opposite direction (positive $\mathrm{x}$ axis) which causes trouble-shooting at this loop. So, in this case, two solenoid valves are initiated to close the pipeline discharges the flow to the leakage location. Fig.16 (d) show the velocity vector at node 19 . At this node 19 the flow separation and vorticity is appeared specially at sharp edges which considered as a considerable leakage value. Fig.16 (c) show the velocity vector at node 14 in the main pipeline. Node 14 velocity vector demonstrates that the maximum flow at this pipeline and the flow direction in negative $\mathrm{Z}$-axis direction, also the vorticity, circulation and separation occurs at nodes aligned with the main pipeline.

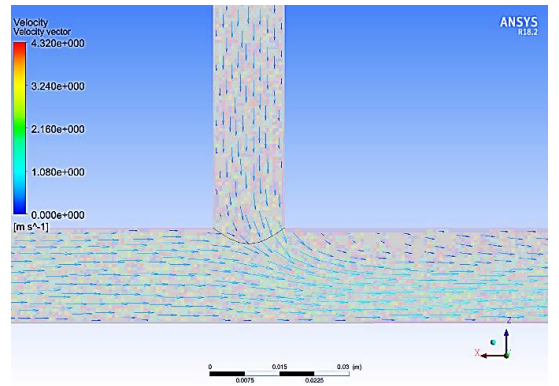

(a) Node 20

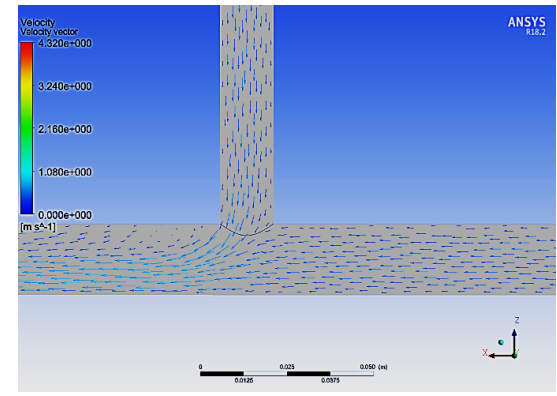

(b) Node 25 


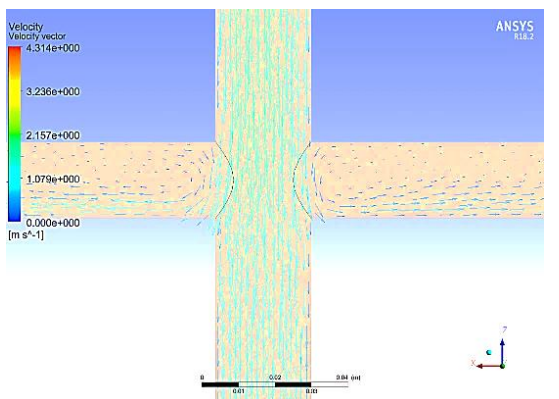

(c) Node 14

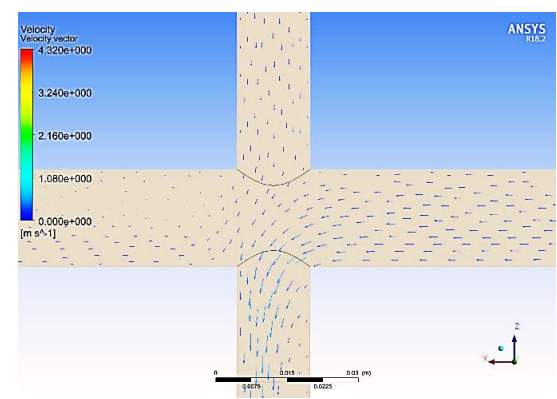

(d) Node 19

Fig.16 Velocity vectors on different nodes with leakage flow rate $0.4 \mathrm{~L} / \mathrm{s}$ at outlet 14

\subsection{CFD Simulation of Leakage at Main Pipeline}

Leakage outlet 15 is located in the leakage design framework at the main pipeline of the water distribution network between nodes 12 and 13. This case is critical because the leakage in the main pipeline causes noticeable change in the network behavior and influences the consumptions everywhere in the network. These leakage flow rate variations enable us to draw a map of pressure variations in the network at different conditions to locate the most affected regions.

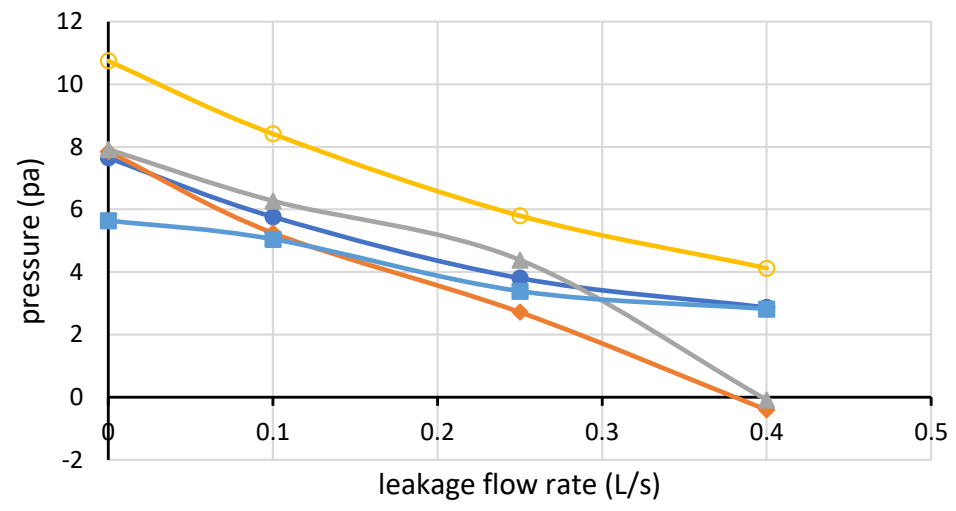

$\multimap$ point $21 \multimap$ point $22 \multimap$ point $23 \multimap$ point $24 \multimap-$ point 25

Fig.17 Pressure at nodes (21-25) versus outlet 15 leakage flow rate variations

Fig. 17 shows the pressure variation at nodes from 21 to 25 with leakage flow rate variation at leakage outlet 15 . Outlet 15 is located at the main pipeline between nodes 12 and 13 . As the leakage flow rate at leakage outlet 15 increases the pressure at nodes 22,23 and 24 decrease to low values but at high leakage flow rate the slope of pressure variation of node 23 higher than other two nodes 22 and 24. The pressure variations curves at nodes 21 and 25 with outlet 15 leakage flow rate variations have small variations.

Fig. 18 shows the pressure variation at nodes from 16 to 20 with leakage flow rate variation at leakage outlet 15 . As the leakage flow rate at outlet 15 increases the pressure at nodes 17, 18 and 19 decrease to low values with different trends. At low leakage flow rate, point 17 has greater slope and its pressure decreases sharply with leakage flow rate variation. At high leakage flow rate, node 18 has greater slope and its pressure highly decreases as 
357 leakage flow rate increases. The pressure values at nodes 16 and 20 due to leakage flow 358 rate variations at outlet 15 have small variations.

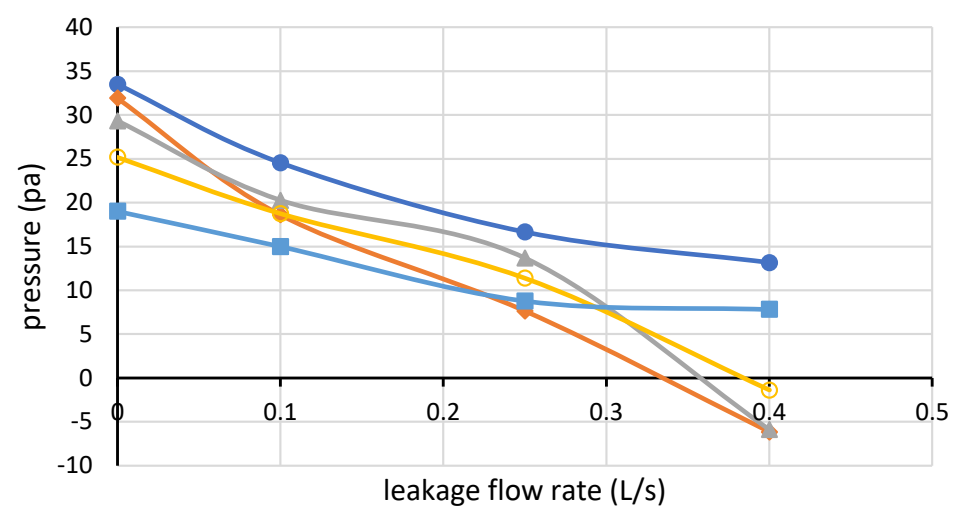

$\multimap$ point $16 \multimap$ point $17 \multimap$ point $18 \multimap$ point $19 \multimap-$ point 20

Fig.18 Pressure at nodes (16-20) versus outlet 15 leakage flow rate variations

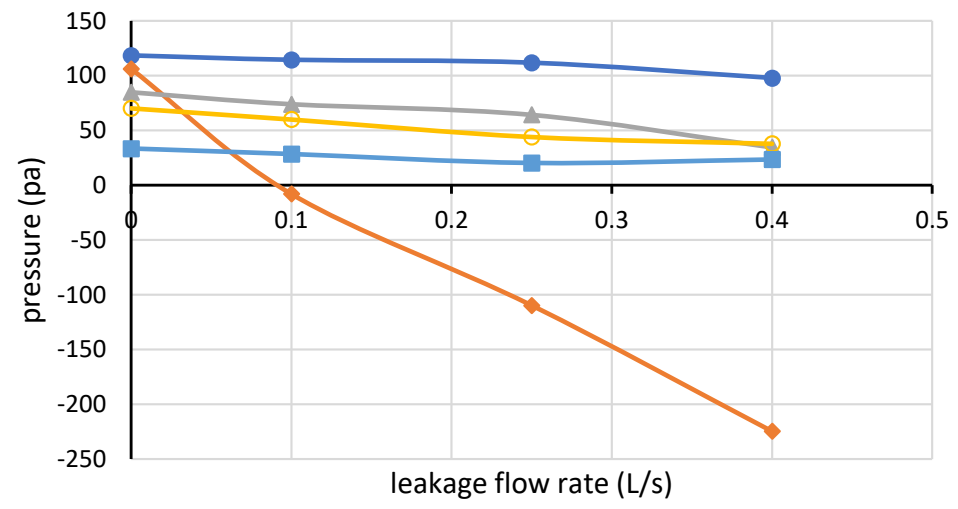

$\multimap$ point $11 \multimap$ point $12 \multimap$ point $13 \multimap$ point $14 \multimap-$ point 15

Fig.19 Pressure at nodes (11-15) versus outlet 15 leakage flow rate variations

Fig. 19 shows the pressure variation at nodes from 11 to 15 with leakage flow rate variation at leakage outlet 15 . The nodes from 11 to 15 are located at the main pipeline. As the leakage flow rate at outlet 15 increases the pressure at node 12 decrease sharply to low values. The pressure variations at nodes $11,13,14$ and 15 with leakage outlet 15 flow rate variations have small variations. 


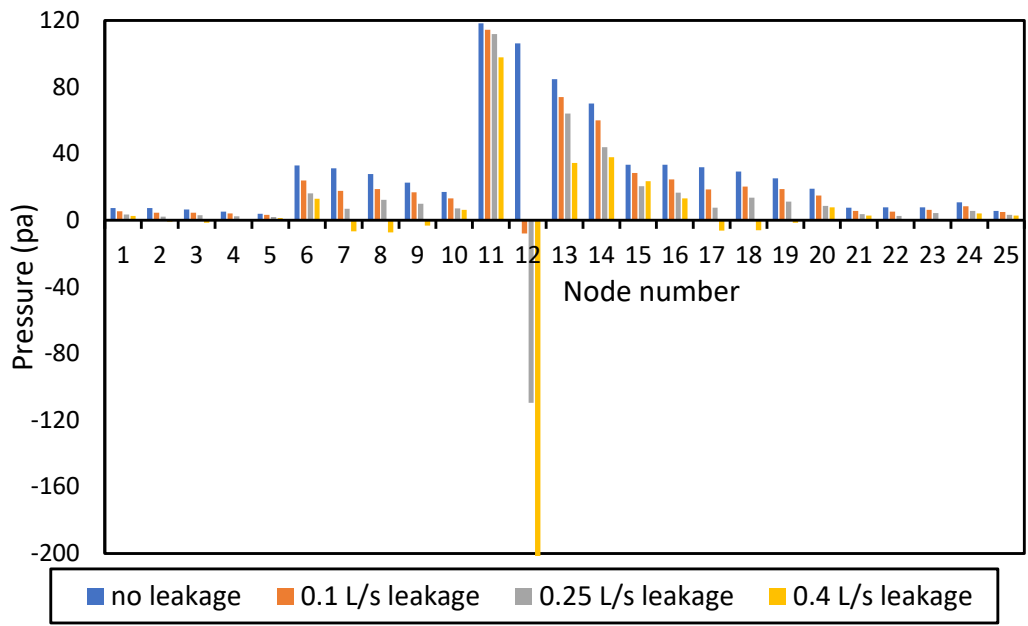

Fig.20 Histogram of pressure variations at all network nodes due to leakage flow rate variations at outlet 15

Fig.20 the histogram shows the pressure variations at all nodes as a result of leakage flow rate variations at designed leakage outlet 15 . The leakage effect is obvious in all extreme nodes of the branches parallel to the part of main pipeline containing the leakage outlet 15 . The effect is noticeable at corner nodes of the two loops that contain the designed leakage outlet 15 in a pipeline considered as a common pipe between these loops due to leakage. Fig. 21 shows the velocity vectors at different nodes of the distribution network in case of leakage at outlet 15 in the main pipeline of the network. Figs.21 (c) and (d) illustrate the velocity vectors of the fluid flow at nodes 12 and 13 . Nodes 12 and 13 are the extreme nodes of the main pipeline of the network containing the leakage outlet 15. Figs.21 (c) and (d) show that the flow direction in this main pipeline is unidirectional from node 12 to node 13 so that the pressure drop due to leakage in this main pipeline has no effect on the flow direction. So, in modification the distribution network to save the water due to leakage one solenoid valves preceding the leakage position on the main pipeline must be used to close the direction to the leakage location. Figs.21 (a) and (b) show the velocity vector at node 17 and 7 in the closest pipeline parallel to the main pipeline containing the leakage. Also, the flow is directed to these nodes to circulate in the loops and finally directed to the leakage outlet due to this is considered the lowest pressure in the network. At these nodes 7 and 17 the flow separation and vorticity are appeared specially at sharp edges as a distribution node which are significant in total leakage calculations and have symmetric flow configurations. 


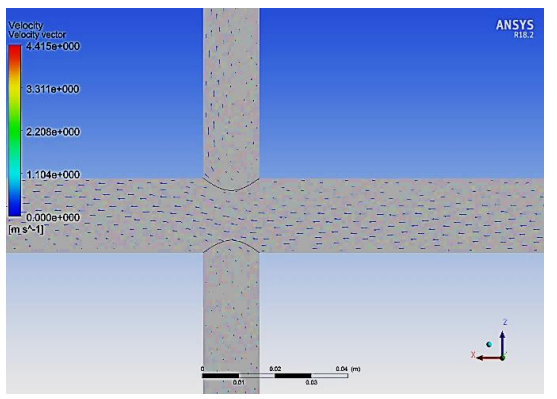

(a) Node 17

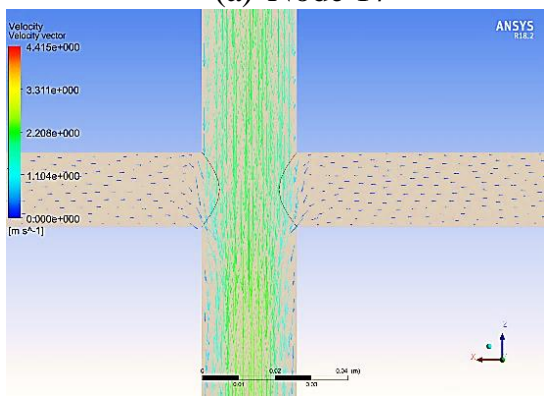

(c) Node 12

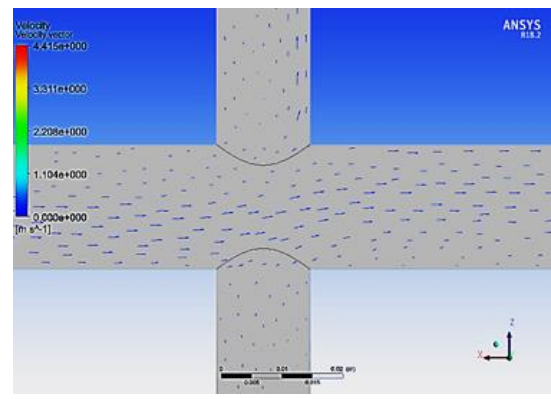

(b) Node 7

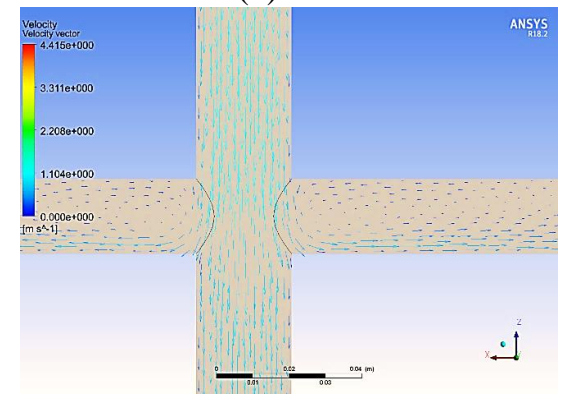

(d) Node 13

Fig. 21 Velocity vectors at different network nodes at leakage flow rate $0.4 \mathrm{~L} / \mathrm{s}$ at outlet 15

\section{Matlab Simulation of Solenoid Valve}

Simulink is a program for simulating any system depending on the derived mathematical model of that system like the integrated distribution network system or any component of the network as the solenoid valve. The solenoid valve actuated by the control circuit due to leakage to close the pipeline directed the flow to the leakage position. The valve actuation response time is investigated due to this response time is a main factor in total leakage calculation. The leakage flow will directly affect the pressure response characteristics of the solenoid valve (Southern, 2016).

Leakage during and after the solenoid valve closing reduces the efficiency and changes the performance of the water distribution network control. The leakage in the solenoid valve is mainly caused by the clearance between the plunger and the casing of the valve at the end of the valve operation, due to the delay of valve time response and the elongation of closing time.

The solenoid valve performance is investigated by deriving the mathematical model of the valve (non-linear differential equations). The deduced mathematical model is used to develop computer simulation program for the studied valve by Matlab-Simulink. The mathematical model consists of continuity equation, flow rate equations and equation of motion. The valve time response is studied under the effect of step pressure signal (Kabib et al., 2016).

The continuity equation in the valve chamber can be represented as:

$$
Q_{i}-Q_{o}-A_{f} \frac{d x}{d t}-\frac{V+A x}{B} \frac{d P}{d t}=0
$$

The valve water inlet flow rate can be calculated as follow: 


$$
\mathrm{Q}_{\mathrm{i}}=\mathrm{C}_{\mathrm{d}} \mathrm{A}_{\mathrm{i}} \sqrt{\frac{2}{\rho}\left(\mathrm{P}_{\mathrm{p}}-\mathrm{P}_{\mathrm{i}}\right)}
$$

The valve water exit flow rate can be calculated as follow:

$$
\mathrm{Q}_{\mathrm{e}}=\mathrm{C}_{\mathrm{d}} \mathrm{A}_{\mathrm{e}} \sqrt{\frac{2}{\rho}\left(\mathrm{P}_{\mathrm{e}}-\mathrm{P}_{\mathrm{a}}\right)}
$$

406 The moving parts can be moved under the action of pressure forces, magnetic force, spring

407 force, inertia force, viscous force and limiting force.

$$
P_{i} A_{f}-P_{e} A_{b}+F_{m}-F_{L}=m \frac{d^{2} x}{d t^{2}}+f \frac{d x}{d t}+k\left(x+x_{o}\right)
$$

The moving part is limited mechanically by the valve body material and a counter reaction 409 force is developed as:

$$
F_{L}=\left\{\begin{array}{cc}
|x| K_{L}+f_{L} \frac{d x}{d t} & x \leq 0 \\
0 & x>0
\end{array}\right.
$$

The magnetic force depends on magnetic field intensity and the magnetic resistance as:

$$
\mathrm{F}_{\mathrm{m}}=\frac{1}{2} \phi_{\text {air }}^{2} \frac{1}{\mu_{\mathrm{o}} \mathrm{A}}
$$

Fig.22 displays the pressure response of the water flow through the solenoid valve due to the step drop of pressure in the main pipeline due to leakage in this line. The simulation shows the step response of the solenoid valve integrated in the distribution network along the main pipeline as the flow pressure in the main pipeline step decreased from 1.8 bar to zero bar (gauge pressure). The solenoid valve in the main pipeline closes immediately the way of flow to the leakage outlet as the drop of pressure is recorded.

Fig. 22 shows that the exit water pressure from the solenoid valve reaches a steady state value equal to the leakage pressure. The response showed over damped high oscillation with a small steady state error about $2 \%$. The steady state error indicates that the valve did not close completely and the leakage still remained but with small amounts. The results show also the settling time of the valve is nearly $0.6 \mathrm{sec}$. This time is taken into consideration when calculating the total leakage amount of water.

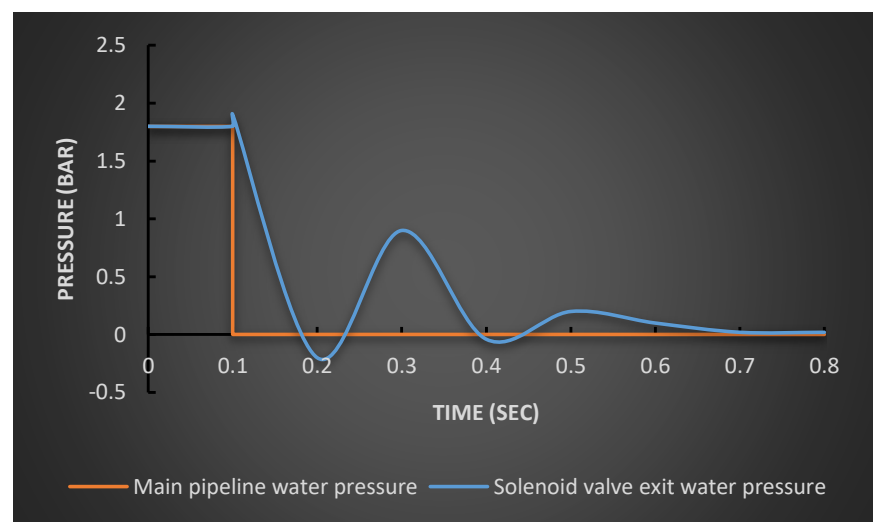

Fig.22 Solenoid valve response to main pipeline water pressure step down variation 
This paper has proposed a new technique of investigation the water leakage effects on the water distribution network performance. This investigation was performed experimentally, theoretically and numerically. There is an agreement between the experimental and numerical results with error range from $9 \%$ to $25 \%$ according to the distance and the path from the leakage outlet to the effected nodes. Theoretical calculations used Hardy-Cross method with seven iterations. Numerical simulation uses Ansys Fluent 18.2 has a benefit as good approach of this study with 480 iterations. The leakage flow rates have values 0.1 , 0.25 and $0.4 \mathrm{~L} / \mathrm{s}$ and changed between the main and sub-main pipes. The research work is limited to small values of leakage flow rate due to the small dimensions of the laboratory network. The maximum pressure drop was 500pa at the node directly preceding the leakage outlet at the leakage flow rate $0.4 \mathrm{~L} / \mathrm{s}$ of the main pipeline. The most influenced nodes are that near to the leakage outlet. The leakage at the main pipeline in the water distribution network is considered the most critical leakage case. The flow direction was reversed and the flow separated in certain leakage cases. The pressure sensors sensed the pressure values and sent signals continually to the control circuit. The control circuit according to the programmed control algorithm gives orders to close the pipelines directed the flow to the leakage outlet by solenoid valves. The cost, the solenoid valves and pressure sensors fixation with linkage to the control circuit are considered the difficulties that can be encountered when implementing this method in a real world situation. Aaccording to the nodes pressure drop and their positions the accurate loci of leakage can be determined. The performance of the used solenoid valve is simulated using Matlab-Simulink technique. The simulation results show the valve response to step down pressure control signal is over damped high oscillatory with a small steady state error $2 \%$ and settling time 0.6 sec.

\section{Nomenclature}

$\mathrm{A}_{\mathrm{f}} \quad$ Valve plunger face area $\left(\mathrm{m}^{2}\right)$

$A_{b} \quad$ Valve plunger back area $\left(\mathrm{m}^{2}\right)$

$\mathrm{A}_{\mathrm{i}} \quad$ Valve inlet orifice area $\left(\mathrm{m}^{2}\right)$

$A_{e} \quad$ Valve exit orifice area $\left(\mathrm{m}^{2}\right)$

B Bulk modulus of water (pa)

$\mathrm{C}_{\mathrm{d}} \quad$ Discharge coefficient

$\mathrm{F}_{\mathrm{L}} \quad$ Valve moving part limiting force $(\mathrm{N})$

$\mathrm{F}_{\mathrm{m}} \quad$ Magnetic force $(\mathrm{N})$

f Friction coefficient (N.s/m)

$\mathrm{f}_{\mathrm{L}} \quad$ Limiter damping coefficient (N.s/m)

k Spring stiffness $(\mathrm{N} / \mathrm{m})$

$\mathrm{k}_{\mathrm{L}} \quad$ Limiter material stiffness $(\mathrm{N} / \mathrm{m})$

$\mathrm{m} \quad$ Valve moving part mass $(\mathrm{kg})$

$\mathrm{P} \quad$ Valve chamber pressure (pa)

$\mathrm{P}_{\mathrm{p}} \quad$ Pump pressure (pa)

$\mathrm{P}_{\mathrm{i}} \quad$ Valve inlet pressure (pa)

$\mathrm{P}_{\mathrm{e}} \quad$ Valve exit pressure (pa)

$\mathrm{P}_{\mathrm{a}} \quad$ Atmospheric pressure (pa)

$\mathrm{Q}_{\mathrm{i}} \quad$ Valve inlet flow rate $(\mathrm{L} / \mathrm{s})$

$\mathrm{Q}_{\mathrm{o}} \quad$ Valve outlet flow rate $(\mathrm{L} / \mathrm{s})$ 
$\mathrm{x} \quad$ Valve plunger displacement (m)

$\mathrm{x}_{\mathrm{o}} \quad$ Spring pre-compression length (m)

V Valve Chamber initial volume $\left(\mathrm{m}^{3}\right)$

$\phi_{\text {air }}$ Magnetic flux of air gab (V.s)

$\mu_{\mathrm{o}} \quad$ Permeability of vacuum $\left(\mathrm{N} / \mathrm{A}^{2}\right)$

\section{Acronyms}

(WDN) Water Distribution Network

(CFD) Computational Fluid Dynamics

(PVC) Polyvinyl Chloride

(CAD) Computer Aided Design

(PRV) Pressure Reducing Valve

\section{REFERENCE}

E. Creaco, G. Pezzinga. Advances in water distribution networks, Water 10,2018, 2-8.

Ahmad Fuad Z., Eddy H. S., Badronnisa Y., Syazwani I., Water leak detection method in water distribution network, Earth and Environmental Science 357,2019.

S. Meniconi, B. Brunone, M. Ferrante, and C. Massari, Numerical and experimental investigation of leaks in viscoelastic pressurized pipe flow, Drinking Water Engineering and Science 6, 2013,11-16.

D. Paluszczyszyn, P. Skworcow, B. Ulanicki, Modelling and simulation of water distribution systems with quantised state system methods, Procedia Engineering 119, 2015, 554-563.

D. Paluszczyszyn, P. Skworcow, B. Ulanicki, A tool for practical simplification of water networks models, Procedia Engineering 119, 2015, 486-495.

E. Creaco and G. Pezzinga, Advances in Water Distribution Networks, Water 10,1546, 2018, 1-8.

E. Creaco and G. Pezzinga, Multiobjective Optimization of Pipe Replacements and Control Valve Installations for Leakage Attenuation in Water Distribution Networks, Journal of Water Resources Planning and Management 141(3), 2014.

G.F. Santonastaso, A. Di Nardo, E. Creaco, Dual topology for partitioning of water distribution networks considering actual valve locations, Urban Water Journal, 2019, 18-34.

Avi Ostfeld, Water Distribution Networks, Studies in Computational Intelligence 565, 2015, 101124.

M. Alsharqawi, T. Zayed, L. Parvizsedghy, H. Al-Derham, Reliability Assessment Model for Water Distribution Networks, Journal of Pipeline Systems Engineering and Practice 11(2), 2020.

D. Starczewska, R.P. Collins, J.B. Boxall, Occurrence of Transients in Water Distribution Networks, Computer Control in water distribution networks conference, Procedia Engineering $119,2015$.

G. Del Giudice and C. Di Cristo, Sampling design for water distribution networks, Second International Conference on Water Resources Management, Water Resources Management II, Volume: 8, 2003

S.M. Kumar, S. Narasimhan, S.M. Bhallamudi, Parameter Estimation in Water Distribution Networks, Water Resources Management 24(6), 2010, 1251-1272.

G. Galuppini, E. Creaco, C. Toffanin, L. Magni, Service Pressure Regulation in Water Distribution Networks, Control Engineering Practice 86, 2019, 70-84.

D. Misiunas, J.P. Vítkovský, G. Olsson, A.R. Simpson, Failure monitoring in water distribution networks, Water Science \& Technology 53(4-5), 2006, 503-11. 
N. Fontana, M. Giugni, L. Glielmo, F. Verrilli, A lab prototype of pressure control in water distribution networks, Water Resources Management 20(1), 2017, 133-149.

M. Romano, Z. Kapelan, Dragan A. Savić, Automated Detection of Pipe Bursts and Other Events in Water Distribution Systems, Journal of Water Resources Planning and Management 140 (4), 2014.

L. Latchoomun, R.T.F. Ah King, K.Busawon, D.Mawooa, R.G.Kaully, Laboratory Investigation of the Leakage Characteristics of Unburied HDPE Pipes, Procedia Engineering 119, 2015, 91 100.

L. Latchoomun, D. Mawooa, Robert T. F. Ah King, K. Busawon, R. Binns, Quantifying the Pumping Energy Loss Associated with Different Types of Leak in a Piping System, International Conference on Emerging Trends in Electrical, Electronic and Communications Engineering, ELECOM 2016, 107-118.

J.E.Van Zyl, Theoretical modeling of pressure and leakage in water distribution systems, Procedia Engineering 89, 2014, 273-277.

D. Paez, C.R. Suribabu, Y. Filion, Method for extended period simulation of water distribution networks with pressure driven demands, Water Resources Management 32(8), 2018, 2837 2846.

M. Straka, D. Malindzak, Classification of distribution networks, Total Logistic Management, 2010, 79-86.

L. Latchoomun, R. Ah King, K. Busawon, A new approach to model development of water distribution networks with high leakage and burst rates, Procedia Engineering 119, 2015, 690699.

M. Mair, W. Rauch, R. Sitzenfrei, Improving incomplete water distribution system data, Procedia Engineering 70, 2014, 1055-1062.

A. Athanasios, D. Kourousis, K. Bollas, Acoustic emission leak detection of liquid filled buried pipeline, Journal of Acoustic Emission 27, 2009.

Mircea Dobriceanu, SCADA system for monitoring water supply networks, WSEAS Transactions on Systems 7.10, 2008, 1070-1079.

B. A. Konnur, R. K. Rai, Optimal Design of Water Transmission Networks', International Journal of Engineering Research 5, 2016, 250-256.

D'Ambrosio Claudia, Mathematical programming techniques in water network optimization, European Journal of Operational Research 243.3, 2015, 774-788.

Marko Blažević, I. Samardžić, Z. Kolumbić, Leak detection in underground pipelines of municipal water distribution, DANUBE Adria Association for Automation and Manufacturing International Conference on Advanced Technologies for Developing Countries, 2005.

Hardy Cross. Analysis of flow in networks of conduits or conductors. Engineering Experiment Station 34, Bulletin No. 286, 1936, 3-29. (online http://hdl.handle.net/2142/4433)

S. El-Zahab, T. Zayed, Leak detection in water distribution networks: an introductory overview, Smart Water 4:5, 2019, 1-23.

K.Y. Volokh, On foundation of the Hardy Cross method, International Journal of Solids and Structures 39 (16), 2002,4197-4200

A.Z. Fuad, H.S. Eddy, Y. Badronnisa, I. Syazwani, Water leak detection method in water distribution network, Earth and Environmental Science 357, 2019.

M. Ferrante, C. Massari, E. Todini, B. Brunone, S. Meniconi, Experimental investigation of leak hydraulics. J. Hydroinformatics 15 (3), 2012, 666-675.

Loan Sarbu, Optimal design of water distribution networks, Journal of Hydraulic Research (1), 2010, 63-79.

J. Chandapillai, K. P. Sudheer, S. Saseendran, Design of Water Distribution Network for Equitable Supply, Water Resources Management 26 (2), 2011. 
M. Afifi, A.Gouniem, M. Farouk, Performance monitoring of water distribution networks using wireless sensor networks, Master of Science, Suez Canal University, 2018.

B. Greyvenstein, J. Van Zyl, An experimental investigation into the pressure-leakage relationship of some failed water pipes, Aqua J. Water Supply Res. Technol. 56 (2), 2007, 117-124.

J.E. Van Zyl, C.R.I. Clayton, The effect of pressure on leakage in water distribution systems. Water management, 160 (2), 2007, 109-114.

ANSYS ICEM CFD 15.0 Tutorial Manual - SAS IP ANSYS, Inc. Southpointe, PA 15317, http://www.ansys.com, 2013.

D. Brki, P. Praks, Short Overview of Early Developments of the Hardy Cross Type Methods for Computation of Flow Distribution in Pipe Networks, Applied Sciences 9, 2019, 1-15.

B.E. Launder, D.B. Spalding, The numerical computation of turbulent flows, Comput. Methods Appl. Mech. Eng. 3, 1974, 269-289.

D. Brki'c, Spreadsheet-based pipe networks analysis for teaching and learning purpose. Spreadsheets Educ. (EJSIE), 2016, 9, 4646. Available online: https://sie.scholasticahq.com/article/4646.pdf.

S.J. Kline, F.A. McClintock, Describing uncertainties in single sample experiments. Mech. Eng. 75, 1953, 3-8.

Jacob D. Southern, Nonlinear Time-Frequency Control of Electromagnetic Solenoid Valve, ASME International Mechanical Engineering Congress and Exposition, 2016.

M. Kabib, I. Made, L. Batan, A. Sigit, Modelling and simulation analysis of solenoid valve for spring constant influence to dynamic response, Journal of Engineering and Applied Sciences 11(4):2790, 2016, 2790-2793. 